\title{
PCR-RFLP assay for species and subspecies differentiation of the Streptococcus bovis group based on groESL sequences
}

Correspondence

Lee-Jene Teng

ljteng@ntu.edu.tw
Received 13 September 2007 Accepted 5 December 2007

\author{
Hsiao-Jan Chen, ${ }^{1}$ Jui-Chang Tsai, ${ }^{2,3}$ Tsung-Chain Chang, ${ }^{4}$ \\ Wei-Chun Hung, ${ }^{1}$ Sung-Pin Tseng, ${ }^{1}$ Po-Ren Hsueh ${ }^{5}$ \\ and Lee-Jene Teng ${ }^{1,5}$ \\ ${ }^{1}$ Department of Clinical Laboratory Sciences and Medical Biotechnology, National Taiwan \\ University College of Medicine, Taipei, Taiwan \\ ${ }^{2}$ Center for Optoelectronic Biomedicine, National Taiwan University College of Medicine, Taipei, \\ Taiwan \\ ${ }^{3}$ Division of Neurosurgery, Department of Surgery, National Taiwan University Hospital, Taipei, \\ Taiwan \\ ${ }^{4}$ Department of Medical Laboratory Science and Biotechnology, School of Medicine, \\ National Cheng Kung University, Tainan, Taiwan \\ ${ }^{5}$ Department of Laboratory Medicine, National Taiwan University Hospital, Taipei, Taiwan
}

The sequence diversity of groESL genes among Streptococcus bovis group isolates was analysed, including five reference strains and 36 clinical isolates. Phylogenetic analysis of the groES and groEL sequences showed that the isolates that belonged to the same species or subspecies usually clustered together. The intergenic spacer region between groES and groEL was variable in size (67-342 bp) and sequence and appeared to be a unique marker for species or subspecies determination. Sequence similarities of the groESL genes among species and subspecies ranged from 84.2 to $99.0 \%$ in groES, and from 88.0 to $99.0 \%$ in groEL. Based on the sequences determined, a Streptococcus bovis group-specific PCR assay was developed, which may provide an alternative means of distinguishing the bovis group from other viridans streptococci. Restriction digestion of the amplicon with Ac/l further differentiated the species and subspecies.

\section{INTRODUCTION}

The 'Streptococcus bovis' group is a large bacterial complex that includes various species and subspecies isolated from humans or animals. In humans, members of the group can cause bacteraemia and endocarditis in elderly people and may sometimes cause septicaemia and meningitis in newborns (Bochud et al., 1994; Gerber et al., 2006; Kupferwasser et al., 1998; Tripodi et al., 2004). The group is also known to be associated with underlying gastrointestinal malignancy (Ellmerich et al., 2000). In previous

\section{Abbreviation: ITS, intergenic spacer.}

The GenBank/EMBL/DDBJ accession numbers for the groESL gene sequences reported in this study are given in Supplementary Table S1 in JMM Online.

Tables showing the GenBank/EMBL/DDBJ accession numbers for the groES and groEL gene sequences of strains used in this study and the nucleotide lengths and sequences of groES-groEL spacer regions are available as supplementary material with the online version of this paper. studies, the authors found that biotype I (Streptococcus gallolyticus) was highly associated with infective endocarditis and colonic cancer, whereas biotype II was associated with primary bacteraemia (Jean et al., 2004; Ruoff et al., 1989). However, the association of species or subspecies and clinical significance is still not clear and sometimes even controversial. To better understand the relationship between pathogens and disease, it is important to identify the species or subspecies correctly.

The taxonomy/nomenclature of members of the Streptococcus bovis group is still evolving. Farrow et al. (1984) identified six different DNA groups in the Streptococcus bovis group using total DNA-DNA hybridization assays. Other investigators further separated the Streptococcus bovis group into five species (S. bovis-S. equinus, S. gallolyticus, S. infantarius, S. pasteurianus and S. lutetiensis) (Facklam, 2002; Osawa et al., 1995; Poyart et al., 2002; Schlegel et al., 2000). According to their biochemical characteristics, Streptococcus bovis strains isolated from humans were divided into three biotypes, 
biotype I (mannitol-positive), II/1 (mannitol-negative and $\beta$-glucuronidase-negative) and II/2 (mannitol-negative and $\beta$-glucuronidase-positive) (Clarridge et al., 2001; Coykendall, 1989). The human isolates of the Streptococcus bovis group have been reclassified as $S$. gallolyticus, $S$. infantarius and $S$. pasteurianus for biotypes I, II/ 1 and II/2, respectively (Poyart et al., 2002; Schlegel et al., 2000). Schlegel et al. (2003) suggested that biotypes I and II/2 and Streptococcus gallolyticus represent a single species and proposed the name Streptococcus gallolyticus subsp. pasteurianus for Streptococcus bovis biotype II/2. Streptococcus bovis biotype II/1 was described as Streptococcus infantarius, with two subspecies, Streptococcus infantarius subsp. infantarius (starch hydrolysis-positive, aesculin hydrolysis-variable and $\beta$-glucosidase-variable) and Streptococcus infantarius subsp. coli (reclassified as Streptococcus lutetiensis) (starch hydrolysis-variable, aesculin hydrolysis-positive and $\beta$-glucosidase-positive) (Facklam, 2002; Schlegel et al., 2000; Poyart et al., 2002). Although these new names have been proposed, most clinical laboratories have not yet accepted the nomenclature. Currently, the identification of the Streptococcus bovis group in clinical laboratories depends mostly on conventional methods and/or rapid identification systems. Misidentification has been reported due to the diversity of the biochemical characteristics of members of the group (Gavin et al., 2002). Molecular-based identification using the sodA gene, encoding manganesedependent superoxide dismutase, has also been used recently for species identification and to distinguish the Streptococcus bovis group (Poyart et al., 1998, 2002; Sasaki et al., 2004). The sequence of the 16S rRNA gene has also been used for phylogenetic analysis (Schlegel et al., 2000, 2003), but it is difficult to differentiate species or subspecies using PCR only.

The groESL genes (also known as cpn10/60 or hsp10/60), which encode $10 \mathrm{kDa}$ (GroES) and $60 \mathrm{kDa}$ (GroEL) heatshock proteins, are ubiquitous and evolutionarily highly conserved among bacteria (Hemmingsen et al., 1988). Amplification of the partial cpn60 (or groEL) gene segment has been used in the identification of bacteria such as Staphylococcus (Goh et al., 1996), Enterococcus (Teng et al., 2001b; Tsai et al., 2005), Streptococcus (Goh et al., 1998; Hung et al., 2005; Teng et al., 2002), Ehrlichia species (Sumner et al., 2000), Bartonella (Marston et al., 1999), Mycobacterium (Rastogi et al., 1999) and rickettsiae (Lee et al., 2003). We have previously determined the groESL sequence of Streptococcus bovis biotype I (Teng et al., 2002). In this study, we determined the groESL sequences of other species and subspecies of the Streptococcus bovis group and analysed the differences between them. Based on these sequences, we have developed a Streptococcus bovis groupspecific PCR. Restriction digestion of the amplicon with Acll further differentiated the species and subspecies.

\section{METHODS}

Bacterial strains. Five reference strains and 36 clinical isolates were used in this study. The reference strains were obtained from the American Type Culture Collection (ATCC) and included
Streptococcus gallolyticus ATCC 9809 (biotype I), Streptococcus gallolyticus subsp. gallolyticus ATCC 43143 (biotype I), Streptococcus infantarius subsp. infantarius ATCC BAA- $102^{\mathrm{T}}$ (biotype II/1), Streptococcus infantarius subsp. coli ATCC BAA-103 (biotype II/1) and Streptococcus gallolyticus subsp. pasteurianus ATCC 43144 (biotype II/2). Twenty-nine of the 36 clinical isolates were collected between 2000 and 2003 in the Bacteriology Laboratory, National Taiwan University Hospital (NTUH), a 2000-bed teaching hospital in northern Taiwan, and the other seven were obtained from the National Cheng Kung University Hospital (NCKUH), a teaching hospital in southern Taiwan. All strains were recovered from blood cultures. The clinical strains were identified to species level and distinguished as Streptococcus gallolyticus $(n=12)$, Streptococcus infantarius II/1 $(n=11)$ and Streptococcus gallolyticus subsp. pasteurianus II/2 ( $n=13)$, by using commercial identification systems [API 20 Strep system (bioMérieux Vitek), Phoenix System or Rapid ID 32 STREP system (bioMérieux Vitek)]. Strains from NCKUH were also identified by using the ribosomal 16S-23S intergenic spacer (ITS) region sequence (Tung et al., 2007).

PCR amplification and sequencing. For the determination of groESL sequences, two sets of PCR were performed. The primers StrepES-UP (5'-GACTATTTCTGACCAAGTGAT-3', located upstream of groES) and Strep-EL-120-100 (5'-CTCAAGAACAACRTTRCGDCC$3^{\prime}$, where $\mathrm{R}$ is $\mathrm{A}$ or $\mathrm{G}$ and $\mathrm{D}$ is $\mathrm{A}$ or $\mathrm{T}$ or $\mathrm{G}$ ), located in the $5^{\prime}$-region of groEL, and which have been described previously (Teng et al., 2002), were used to amplify a fragment containing the entire groES gene, ITS region and the short $5^{\prime}$-end region of groEL. The primers bovis-1F ( $5^{\prime}$-TCAGGACATTTTGCCACTTCTT-3', corresponding to positions 684-705 of the groEL gene) and Gor1907-1927 (5'YTACATCATNCCNCCCATCAT- $3^{\prime}$, where $\mathrm{Y}$ is $\mathrm{C}$ or $\mathrm{T}$ and $\mathrm{N}$ is A, $\mathrm{T}, \mathrm{C}$ or G), corresponding to positions $1623-1603$ of the groEL gene, were used to amplify a partial groEL gene. PCR was carried out using a DNA thermal cycler (MJ Research) with 30 cycles of denaturation $\left(94{ }^{\circ} \mathrm{C}, 30 \mathrm{~s}\right)$, annealing $\left(50{ }^{\circ} \mathrm{C}, 30 \mathrm{~s}\right)$ and extension $\left(72{ }^{\circ} \mathrm{C}, 1 \mathrm{~min}\right)$, followed by a final extension step $\left(72{ }^{\circ} \mathrm{C}, 10 \mathrm{~min}\right)$. The PCR products were purified and subsequently sequenced using a sequencing system (model ABI PRISM 3100; Applied Biosystems) with a Taq BigDyeDeoxy Terminator cycle sequencing kit (Applied Biosystems), according to the instructions of the manufacturer.

Phylogenetic analysis. The phylogenetic relationships among species were analysed by using the neighbour-joining method in the MEGA2 (molecular evolutionary genetic analysis) analytical package (Kumar et al., 2001). For the neighbour-joining analysis, the distance between the sequences was calculated using Kimura's two-parameter model. Levels of similarity among species were determined. Bootstrap values were obtained for 500 randomly generated trees.

Intraspecies and interspecies variation. The intraspecies variation of groES genes, ITS region and partial groEL genes and the interspecies variation of groES and groEL genes were evaluated among the clinical isolates. The strains were subjected to PCR amplification of groES and ITS region with primers Strep-ES-UP and Strep-EL-120-100. PCR with primers bovis-1F and Gor1907-1927 was performed to amplify partial groEL genes. The amplified PCR products were subsequently sequenced. DNA and deduced amino acid sequences were aligned using Gene-Works software (IntelliGenetics).

Streptococcus bovis group-specific PCR. Based on the sequence obtained, we developed a Streptococcus bovis group-specific PCR. The forward primer ES5-29F (5'-TAAAACCHTTAGGHGAHCGWRTBGT$\left.3^{\prime}\right)$, together with the reverse primer, Streptococcus bovis EL1265R (5' CAAGTTCAAGTTCAGCAACTTTTG-3'), were derived to amplify a target region with an amplicon size that ranged from 1635 to $1910 \mathrm{bp}$, depending on the species. PCR was performed with 35 cycles of denaturation $\left(94{ }^{\circ} \mathrm{C}, 30 \mathrm{~s}\right)$, annealing $\left(54{ }^{\circ} \mathrm{C}, 30 \mathrm{~s}\right)$ and extension 
$\left(72{ }^{\circ} \mathrm{C}, 2 \mathrm{~min}\right)$, followed by a final extension step $\left(72{ }^{\circ} \mathrm{C}, 10 \mathrm{~min}\right)$. The PCR products were analysed by using agarose gel electrophoresis $(1.5 \%$ agarose; FMC BioProducts), and then stained with ethidium bromide and photographed under UV light. A visible band with a size of 1.6$1.9 \mathrm{~kb}$ was considered to be a positive reaction.

PCR-RFLP for species and subspecies differentiation. After PCR, a restriction analysis was performed to further differentiate between species and subspecies. The amplification product was digested with the restriction enzyme AclI (New England BioLabs). After incubation, the DNA fragments were subjected to gel electrophoresis (FMC BioProducts), stained with ethidium bromide and photographed under UV light.

\section{RESULTS AND DISCUSSION}

\section{Nucleotide sequences of groESL genes in reference strains}

The nucleotide sequences of full-length groES and partial groEL genes were determined for five reference strains. The sequences showed that the groES genes were all $285 \mathrm{bp}$ in length. The similarities between the groES sequences ranged from $84.2 \%$ (between Streptococcus infantarius subsp. infantarius ATCC BAA- $102^{\mathrm{T}}$ and both Streptococcus gallolyticus ATCC 9809 and Streptococcus gallolyticus subsp. pasteurianus ATCC 43144) to $99.0 \%$ (between Streptococcus gallolyticus subsp. pasteurianus ATCC 43144 and Streptococcus gallolyticus ATCC 9809) at the nucleotide sequence level (Table 1). Pairwise sequence similarity of partial groEL (nucleotide positions 883-1572) among species and subspecies tested with reference strains ranged from $88.0 \%$ (between Streptococcus gallolyticus ATCC 9809 and Streptococcus infantarius subsp. infantarius ATCC BAA- $102^{\mathrm{T}}$ ) to $98.8 \%$ (between Streptococcus gallolyticus ATCC 9809 and Streptococcus gallolyticus subsp. pasteurianus ATCC 43144) (Table 1).

The length of the ITS region between groES and groEL was also found to be species and subspecies specific. The ITS regions in two Streptococcus gallolyticus reference strains, Streptococcus gallolyticus ATCC 9809 and Streptococcus gallolyticus subsp. gallolyticus ATCC 43143, were of the same length (67 bp), which was $2 \mathrm{bp}$ less than that (69 bp) in Streptococcus gallolyticus subsp. pasteurianus ATCC 43144. The size of the ITS regions in Streptococcus infantarius and two subspecies of Streptococcus infantarius (Streptococcus infantarius subsp. infantarius ATCC BAA$102^{\mathrm{T}}$ and Streptococcus infantarius subsp. coli ATCC BAA103) was the same ( $342 \mathrm{bp}$ ), but the sequences differed in 6 nucleotides (see Supplementary Table S2 available in JMM Online).

\section{Intraspecies similarities in clinical isolates}

To evaluate the general applicability of the groESL sequence to species and subspecies identification, the groES and partial groEL sequences and the ITS regions of 36 clinical isolates were tested to identify intraspecies similarities. Comparison of these sequences from clinical isolates with reference strains for each species or subspecies are shown in Table 2. The intraspecies identity of groES was slightly higher than that for groEL sequences (Table 2). The ITS sequences from the Streptococcus gallolyticus clinical isolates were the most divergent, ranging from 95.5 to $100 \%$.

The ITS region between groES and groEL appeared to be another useful marker for species or subspecies differentiation. The lengths of the ITS regions of the clinical isolates were 67 (Streptococcus gallolyticus), 68 or 69 bp (Streptococcus gallolyticus subsp. pasteurianus) and $342 \mathrm{bp}$ (Streptococcus infantarius), respectively. However, minor sequence variation was observed.

We found that the groES or groEL sequences provided more discrimination than the $16 \mathrm{~S}$ rRNA gene for the differentiation of species and subspecies within the Streptococcus bovis group. The difference in the sequences of the 16S rRNA gene between Streptococcus gallolyticus and Streptococcus gallolyticus subsp. pasteurianus is only $0.3 \%$, whereas the differences in groES and groEL were more than $1.0 \%$. The higher interspecies divergence will make the differentiation easier. In addition to the low intraspecies variation of groESL sequences among the Streptococcus bovis group, these findings are attractive for species identification among this group.

Table 1. groES and groEL sequence similarities among reference strains

Data in the upper right portion indicate groES gene sequence similarity and data in the lower left portion indicate groEL gene sequence similarity. The numbers in the column headings represent the species numbered in the leftmost column.

\begin{tabular}{|c|c|c|c|c|c|c|}
\hline \multirow[t]{2}{*}{ Species } & \multirow[t]{2}{*}{ Biotype } & \multicolumn{5}{|c|}{ Sequence similarity (\%) } \\
\hline & & 1 & 2 & 3 & 4 & 5 \\
\hline 1. Streptococcus gallolyticus ATCC 9809 & I & - & 99.7 & 84.2 & 84.6 & 99.0 \\
\hline 2. Streptococcus gallolyticus subsp. gallolyticus ATCC 43143 & I & 99.7 & - & 84.6 & 84.9 & 99.0 \\
\hline 3. Streptococcus infantarius subsp. infantarius ATCC BAA-102 ${ }^{\mathrm{T}}$ & $\mathrm{II} / 1$ & 88.0 & 88.3 & - & 99.7 & 84.2 \\
\hline 4. Streptococcus infantarius subsp. coli ATCC BAA-103 & $\mathrm{II} / 1$ & 88.7 & 89.0 & 97.1 & - & 84.6 \\
\hline 5. Streptococcus gallolyticus subsp. pasteurianus ATCC 43144 & $\mathrm{II} / 2$ & 98.8 & 99.0 & 88.0 & 88.8 & - \\
\hline
\end{tabular}


Table 2. Intraspecies variation of groES, groEL and ITS regions of the clinical isolates

\begin{tabular}{|c|c|c|c|c|c|c|c|}
\hline \multirow[t]{2}{*}{ Species } & \multirow[t]{2}{*}{$\begin{array}{c}\text { Biotype } \\
\text { (no. of isolates) }\end{array}$} & \multicolumn{2}{|c|}{$\begin{array}{c}\text { groES } \\
\text { (full-length, } 285 \text { bp) }\end{array}$} & \multicolumn{2}{|c|}{ ITS region } & \multicolumn{2}{|c|}{$\begin{array}{c}\text { Partial groEL } \\
\text { (nt positions 883-1572) }\end{array}$} \\
\hline & & $\begin{array}{l}\text { No. of different } \\
\text { nucleotides }\end{array}$ & $\begin{array}{l}\text { Percentage } \\
\text { identity }\end{array}$ & $\begin{array}{l}\text { No. of different } \\
\text { nucleotides }\end{array}$ & $\begin{array}{l}\text { Percentage } \\
\text { identity }\end{array}$ & $\begin{array}{l}\text { No. of different } \\
\text { nucleotides }\end{array}$ & $\begin{array}{l}\text { Percentage } \\
\text { identity }\end{array}$ \\
\hline Streptococcus gallolyticus & I (12) & $0-4$ & $98.6-100$ & $0-3$ & $95.5-100$ & $0-4$ & $99.4-100$ \\
\hline Streptococcus infantarius & II/1 (11) & $0-1$ & $99.7-100$ & $0-7$ & $98.0-100$ & $1-23$ & $96.7-99.9$ \\
\hline
\end{tabular}

\section{Phylogenetic relationships}

Unrooted phylogenetic trees constructed from full-length groES and partial groEL (nucleotide positions 883-1572) from the 36 clinical isolates and five reference strains are presented in Fig. 1. The phylogenetic analysis revealed that the nucleotide sequences of groES from 41 tested strains were divided into three major clusters, which were consistent with species and subspecies. The results of the phylogenetic analysis of the groEL gene were similar to those for the groES gene. The clinical isolates of biotype II/1 all clustered with Streptococcus infantarius subsp. coli ATCC BAA-103. In agreement with the 16S rRNA gene analysis, phylogenetic analysis of groES or groEL revealed that Streptococcus gallolyticus subsp. pasteurianus was more closely related to Streptococcus gallolyticus than to Streptococcus infantarius.

\section{Streptococcus bovis group-specific PCR}

Based on the sequences determined in this study, a pair of primers, ES5-29F and Streptococcus bovis EL1265R, was designed for Streptococcus bovis group-specific PCR. The specificity of the primers was tested with four reference strains and clinical isolates of the Streptococcus bovis group and 19 reference strains of other common Gram-positive bacteria, including Streptococcus criceti E49 (serotype a), Streptococcus rattiEA1 (serotype b), Streptococcus mutans GS-5 (serotype c), Streptococcus sobrinus B13 (serotype d), Streptococcus mutans MT730R (serotype e), Streptococcus mutans OME175 (serotype f), Streptococcus sobrinus 6715 (serotype g), Streptococcus sobrinus MFe28 (h), Streptococcus pyogenes ATCC 19615, Streptococcus anginosus ATCC $33397^{\mathrm{T}}$, Streptococcus gordonii ATCC $10558^{\mathrm{T}}$, Streptococcus mitis ATCC 49456, Streptococcus constellatus subsp. constellatus ATCC $27823^{\mathrm{T}}$, Streptococcus sanguinis ATCC $10556^{\mathrm{T}}$, Streptococcus oralis ATCC $35037^{\mathrm{T}}$, Streptococcus agalactiae ATCC $13813^{\mathrm{T}}$, Enterococcus faecium ATCC 35667, Enterococcus casseliflavus ATCC $25788^{\mathrm{T}}$ and Gemella haemolysans ATCC $10379^{\mathrm{T}}$. Four reference strains of the Streptococcus bovis group generated amplicons of the size expected: 1635 bp for Streptococcus gallolyticus, 1637 bp for Streptococcus gallolyticus subsp. pasteurianus and $1910 \mathrm{bp}$ for Streptococcus infantarius (Fig. 2a). None of the other bacterial species tested generated products of similar size (data not shown). Amplification using clinical isolates, including the Streptococcus bovis group and other bacteria, gave the same results as the corresponding reference strains (part of the data are shown in Fig. 2a).

The Streptococcus bovis group-specific PCR detected all species and subspecies of the Streptococcus bovis group isolated from humans and could distinguish members of the Streptococcus bovis group from other bacteria, whereas PCR developed by other investigators usually resulted in the detection of only one or two species or subspecies of the Streptococcus bovis group. For example, the sodA gene has been reported previously to be an alternative target for Streptococcus gallolyticus (biotype I and II/2)-specific PCR (Sasaki et al., 2004).

\section{PCR-RFLP for differentiation of species and subspecies}

To further differentiate between species and subspecies, an AclI restriction enzyme analysis was performed (Fig. 2b). The PCR-RFLP patterns from different species and subspecies were distinguishable (Fig. 2b). Using this assay, Streptococcus gallolyticus and Streptococcus gallolyticus subsp. pasteurianus were clearly separated. All clinical isolates of Streptococcus gallolyticus and Streptococcus gallolyticus subsp. pasteurianus tested also yielded identical patterns to those of the corresponding reference strains. Two reference strains representing two subspecies of Streptococcus infantarius, Streptococcus infantarius subsp. infantarius ATCC BAA- $102^{\mathrm{T}}$ and Streptococcus infantarius subsp. coli ATCC BAA-103, generated similar but different PCR-RFLP patterns (Fig. 2b).

We checked the restriction patterns shown in the gel in Fig. $2 \mathrm{~b}$ with the sizes estimated from the sequence data. According to the sequence data, the PCR products of Streptococcus gallolyticus were expected to be digested into five fragments $(495,363,299,286$ and $171 \mathrm{bp})$ using the restriction enzyme Acll. Among these fragments, the 299 and $286 \mathrm{bp}$ fragments are too close in size and could not be discriminated by gel electrophoresis; therefore, only four bands can be seen in the gel. The restriction fragments of the amplicon from Streptococcus gallolyticus subsp. pasteurianus showed the expected sizes $(667,495,286$ and $171 \mathrm{bp})$. Five restriction fragments of the amplicon were expected (733, 702, 286, 161 and $10 \mathrm{bp})$ for Streptococcus infantarius subsp. infantarius and four fragments $(733,702$, 


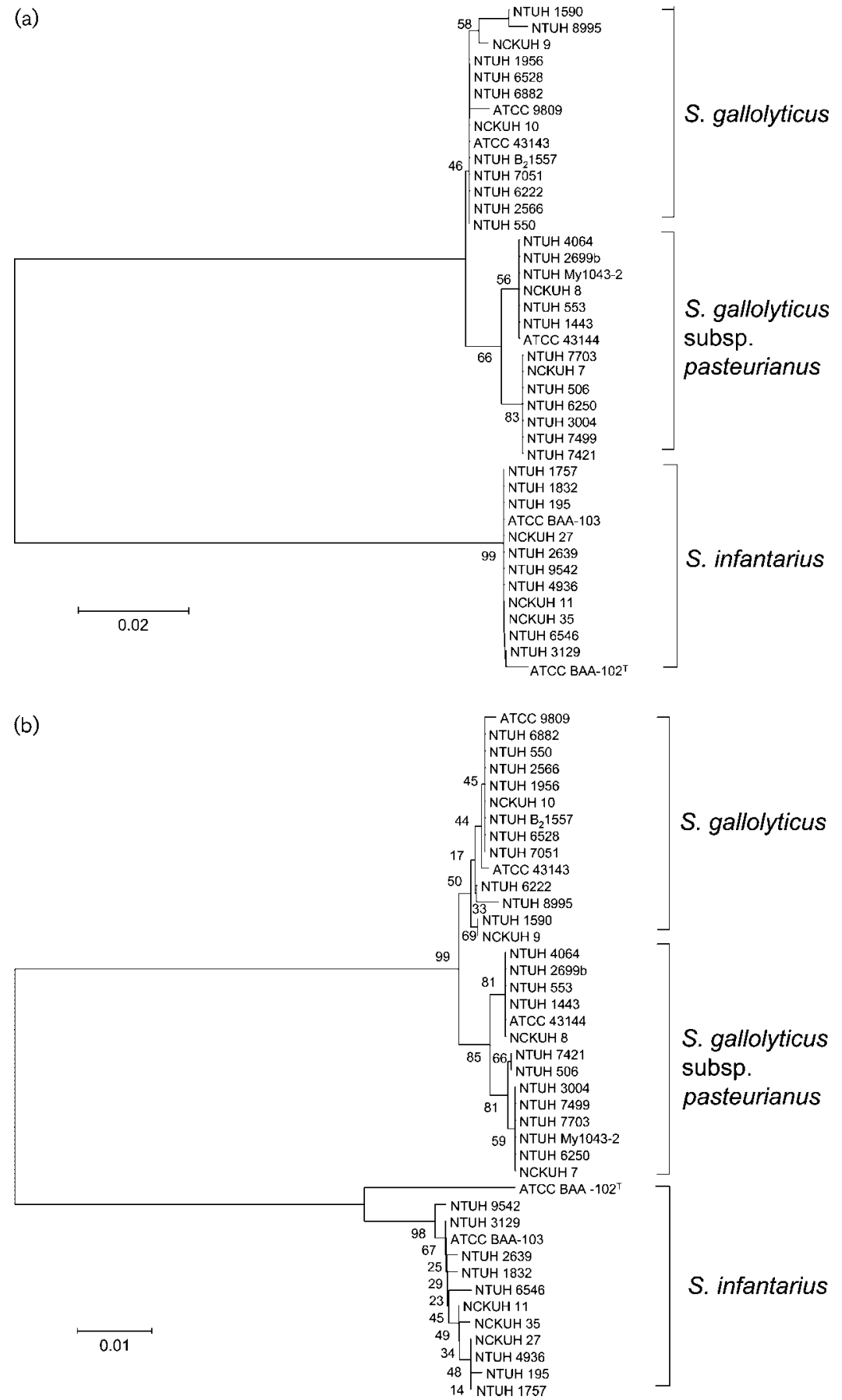

Fig. 1. Phylogenetic relationships among Streptococcus bovis group isolates (including reference strains and clinical isolates) based on the nucleotide sequences of (a) groES and (b) groEL genes. The phylogenetic trees were generated by using the neighbour-joining method in the MEGA2 package. Numbers at nodes are confidence levels expressed as percentages of occurrence in 500 bootstrapped resamplings. Scale bars indicate the evolutionary distance between sequences determined by measuring the lengths of the horizontal lines connecting two organisms. GenBank accession numbers for the gene sequences used are available in Supplementary Table S1 in JMM Online.

447 and $10 \mathrm{bp}$ ) for Streptococcus infantarius subsp. coli. As the $10 \mathrm{bp}$ fragment was too small to be seen using electrophoresis, only three fragments were shown in Streptococcus infantarius subsp. coli. The PCR-RFLP patterns obtained for all clinical isolates of biotype II/1 were identical to that of Streptococcus infantarius subsp. coli ATCC BAA-103.

Differentiation of species and subspecies within the Streptococcus bovis group is important clinically. The association of species and subspecies with types of infection and underlying diseases has been reported previously (Jean et al., 2004; Ruoff et al., 1989). In many reports, Streptococcus gallolyticus was more commonly associated with colorectal carcinoma than other species and subspecies (Ruoff et al., 1989), whereas Streptococcus gallolyticus subsp. pasteurianus was more frequently associated with neonatal meningitis. Clarridge et al. (2001) reported that biotype II/2 (Streptococcus gallolyticus subsp. pasteurianus) formed a separate genospecies and was the most common in adult males. This hypothesis has been confirmed by additional taxonomic studies conducted 
(a)

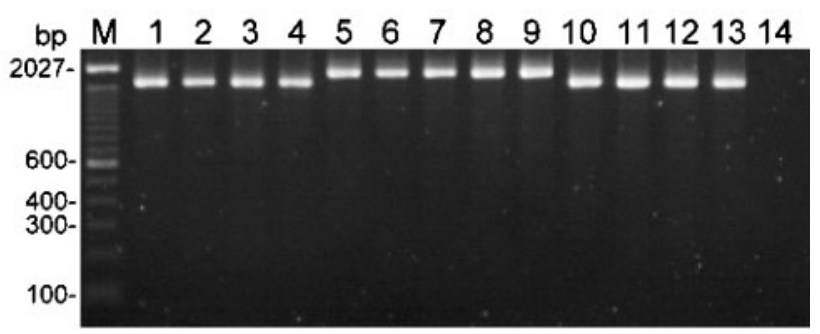

(b)

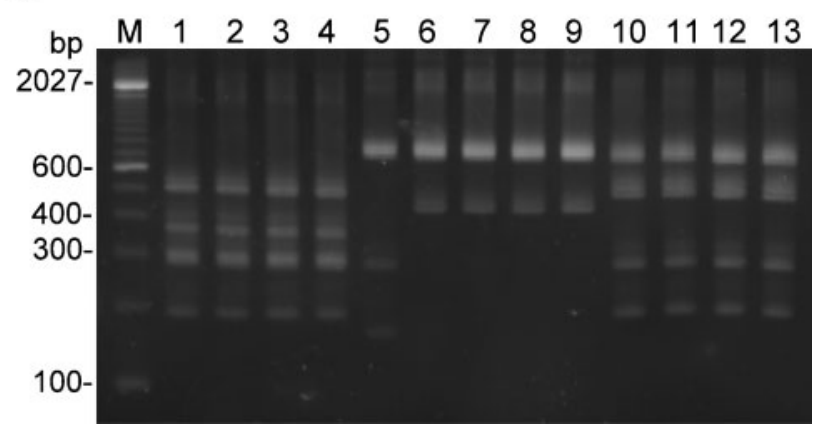

Fig. 2. Streptococcus bovis group-specific PCR and RFLP analysis of the groESL genes among species and subspecies of the Streptococcus bovis group. (a) Streptococcus bovis groupspecific PCR. (b) Restriction fragments of amplified products after Acll digestion. Lanes: M, 100 bp DNA ladder; 1-4, Streptococcus gallolyticus (biotype I) (strains ATCC 9809, NTUH 7051, NTUH 6222 and NTUH 8995); 5, Streptococcus infantarius subsp. infantarius ATCC BAA $-102^{\top}$ (biotype II/1); 6, Streptococcus infantarius subsp. coli ATCC BAA-103 (biotype II/1); 7-9, clinical isolates of Streptococcus infantarius (biotypes II/1) (strains NTUH 4936, NTUH 195 and NTUH 2639); 10-13, Streptococcus gallolyticus subsp. pasteurianus (biotype II/2) (strains ATCC 43144, NTUH 3004, NTUH 1443 and NTUH 7499); 14, negative control.

by other teams (Poyart et al. 2002; Schlegel et al. 2003). In Taiwan, Streptococcus bovis biotype I has been correlated with infective endocarditis (Jean et al., 2004). In addition to the pathogenesis, different species and subspecies may display distinct antimicrobial patterns. We have reported that the prevalence of inducible erythromycin resistance among Streptococcus gallolyticus subsp. pasteurianus was higher than that of other species and subspecies (Teng et al., 2001a).

One limitation of the present study is that only human isolates were included. Avian isolates may show different geno- or phenotypes (Chadfield et al., 2007). In summary, based on the groESL sequences determined, we have developed a Streptococcus bovis group-specific PCR assay that may provide an alternative way of distinguishing the Streptococcus bovis group from other viridans streptococci. Restriction digestion of the amplicon with Acll improved the differentiation between the predominant human species or subspecies of the Streptococcus bovis group.

\section{REFERENCES}

Bochud, P. Y., Calandra, T. \& Francioli, P. (1994). Bacteremia due to viridans streptococci in neutropenic patients: a review. Am J Med 97, 256-264.

Chadfield, M. S., Christensen, J. P., Decostere, A., Christensen, H. \& Bisgaard, M. (2007). Geno- and phenotypic diversity of avian isolates of Streptococcus gallolyticus subsp. gallolyticus (Streptococcus bovis) and associated diagnostic problems. J Clin Microbiol 45, 822-827.

Clarridge, J. E., III, Attorri, S. M., Zhang, Q. \& Bartell, J. (2001). 16S ribosomal DNA sequence analysis distinguishes biotypes of Streptococcus bovis: Streptococcus bovis Biotype II/2 is a separate genospecies and the predominant clinical isolate in adult males. J Clin Microbiol 39, 1549-1552.

Coykendall, A. L. (1989). Classification and identification of the viridans streptococci. Clin Microbiol Rev 2, 315-328.

Ellmerich, S., Scholler, M., Duranton, B., Gosse, F., Galluser, M., Klein, J. P. \& Raul, F. (2000). Promotion of intestinal carcinogenesis by Streptococcus bovis. Carcinogenesis 21, 753-756.

Facklam, R. (2002). What happened to the streptococci: overview of taxonomic and nomenclature changes. Clin Microbiol Rev 15, 613-630.

Farrow, J. A. E., Kruze, J., Phillips, B. A., Bramley, A. J. \& Collins, M. D. (1984). Taxonomic studies on Streptococcus bovis and Streptococcus equinus: description of Streptococcus alactolyticus sp. nov. and Streptococcus saccharolyticus sp. nov. Syst Appl Microbiol 5, 467-482.

Gavin, P. J., Warren, J. R., Obias, A. A., Collins, S. M. \& Peterson, L. R. (2002). Evaluation of the Vitek 2 system for rapid identification of clinical isolates of gram-negative bacilli and members of the family Streptococcaceae. Eur J Clin Microbiol Infect Dis 21, 869-874.

Gerber, J. S., Glas, M., Frank, G. \& Shah, S. S. (2006). Streptococcus bovis infection in young infants. Pediatr Infect Dis J 25, 1069-1073.

Goh, S. H., Potter, S., Wood, J. O., Hemmingsen, S. M., Reynolds, R. P. \& Chow, A. W. (1996). HSP60 gene sequences as universal targets for microbial species identification: studies with coagulase-negative staphylococci. J Clin Microbiol 34, 818-823.

Goh, S. H., Driedger, D., Gillett, S., Low, D. E., Hemmingsen, S. M., Amos, M., Chan, D., Lovgren, M., Willey, B. M. \& other authors (1998). Streptococcus iniae, a human and animal pathogen: specific identification by the chaperonin 60 gene identification method. J Clin Microbiol 36, 2164-2166.

Hemmingsen, S. M., Woolford, C., van der Vies, S. M., Tilly, K., Dennis, D. T., Georgopoulos, C. P., Hendrix, R. W. \& Ellis, R. J. (1988). Homologous plant and bacterial proteins chaperone oligomeric protein assembly. Nature 333, 330-334.

Hung, W.-C., Tsai, J.-C., Hsueh, P.-R., Chia, J.-S. \& Teng, L.-J. (2005). Species identification of mutans streptococci by groESL gene sequence. J Med Microbiol 54, 857-862.

Jean, S. S., Teng, L. J., Hsueh, P. R., Ho, S. W. \& Luh, K. T. (2004). Bacteremic Streptococcus bovis infections at a university hospital, 1992-2001. J Formos Med Assoc 103, 118-123.

Kumar, S., Tamura, K., Jakobsen, I. B. \& Nei, M. (2001). MEGA2: molecular evolutionary genetics analysis software. Bioinformatics 17, 1244-1245.

Kupferwasser, I., Dariu, H., Muller, A. M., Mohr-Kahaly, S., Westermeier, T., Oelert, H., Erbel, R. \& Meyer, J. (1998). Clinical and morphological characteristics in Streptococcus bovis endocarditis: a comparison with other causative microorganisms in 177 cases. Heart 80, 276-280.

Lee, J. H., Park, H. S., Jang, W. J., Koh, S. E., Kim, J. M., Shim, S. K., Park, M. Y., Kim, Y. W., Kim, B. J. \& other authors (2003). 
Differentiation of rickettsiae by groEL gene analysis. J Clin Microbiol 41, 2952-2960.

Marston, E. L., Sumner, J. W. \& Regnery, R. L. (1999). Evaluation of intraspecies genetic variation within the $60 \mathrm{kDa}$ heat-shock protein gene (groEL) of Bartonella species. Int J Syst Bacteriol 49, 1015-1023.

Osawa, R., Fujisawa, T. \& Sly, L. L. (1995). Streptococcus gallolyticus sp. nov.; gallate degrading organisms formerly assigned to Streptococcus bovis. Syst Appl Microbiol 18, 74-78.

Poyart, C., Quesne, G., Coulon, S., Berche, P. \& Trieu-Cuot, P. (1998). Identification of streptococci to species level by sequencing the gene encoding the manganese-dependent superoxide dismutase. $J$ Clin Microbiol 36, 41-47.

Poyart, C., Quesne, G. \& Trieu-Cuot, P. (2002). Taxonomic dissection of the Streptococcus bovis group by analysis of manganese-dependent superoxide dismutase gene ( $\operatorname{sod} A)$ sequences: reclassification of 'Streptococcus infantarius subsp. coli' as Streptococcus lutetiensis sp. nov. and of Streptococcus bovis biotype 11.2 as Streptococcus pasteurianus sp. nov. Int J Syst Evol Microbiol 52, 1247-1255.

Rastogi, N., Goh, K. S. \& Berchel, M. (1999). Species-specific identification of Mycobacterium leprae by PCR-restriction fragment length polymorphism analysis of the hsp65 gene. J Clin Microbiol 37, 2016-2019.

Ruoff, K. L., Miller, S. I., Garner, C. V., Ferraro, M. J. \& Calderwood, S. B. (1989). Bacteremia with Streptococcus bovis and Streptococcus salivarius: clinical correlates of more accurate identification of isolates. $J$ Clin Microbiol 27, 305-308.

Sasaki, E., Osawa, R., Nishitani, Y. \& Whiley, R. A. (2004). Development of a diagnostic PCR assay targeting the Mn-dependent superoxide dismutase gene $(\operatorname{sod} A)$ for identification of Streptococcus gallolyticus. J Clin Microbiol 42, 1360-1362.

Schlegel, L., Grimont, F., Collins, M. D., Regnault, B., Grimont, P. A. \& Bouvet, A. (2000). Streptococcus infantarius sp. nov., Streptococcus infantarius subsp. infantarius subsp. nov. and Streptococcus infantarius subsp. coli subsp. nov., isolated from humans and food. Int J Syst Evol Microbiol 50, 1425-1434.

Schlegel, L., Grimont, F., Ageron, E., Grimont, P. A. \& Bouvet, A. (2003). Reappraisal of the taxonomy of the Streptococcus bovis/ Streptococcus equinus complex and related species: description of Streptococcus gallolyticus subsp. gallolyticus subsp. nov., S. gallolyticus subsp. macedonicus subsp. nov. and S. gallolyticus subsp. pasteurianus subsp. nov. Int J Syst Evol Microbiol 53, 631-645.

Sumner, J. W., Storch, G. A., Buller, R. S., Liddell, A. M., Stockham, S. L., Rikihisa, Y., Messenger, S. \& Paddock, C. D. (2000). PCR amplification and phylogenetic analysis of groESL operon sequences from Ehrlichia ewingii and Ehrlichia muris. J Clin Microbiol 38, 2746-2749.

Teng, L. J., Hsueh, P. R., Ho, S. W. \& Luh, K. T. (2001a). High prevalence of inducible erythromycin resistance among Streptococcus bovis isolates in Taiwan. Antimicrob Agents Chemother 45, 3362-3365.

Teng, L. J., Hsueh, P. R., Wang, Y. H., Lin, H. M., Luh, K. T. \& Ho, S. W. (2001b). Determination of Enterococcus faecalis groESL full-length sequence and application for species identification. J Clin Microbiol 39, 3326-3331.

Teng, L. J., Hsueh, P. R., Tsai, J. C., Chen, P. W., Hsu, J. C., Lai, H. C., Lee, C. N. \& Ho, S. W. (2002). groESL sequence determination, phylogenetic analysis, and species differentiation for viridans group streptococci. J Clin Microbiol 40, 3172-3178.

Tripodi, M. F., Adinolfi, L. E., Ragone, E., Durante Mangoni, E., Fortunato, R., larussi, D., Ruggiero, G. \& Utili, R. (2004). Streptococcus bovis endocarditis and its association with chronic liver disease: an underestimated risk factor. Clin Infect Dis 38, 1394-1400.

Tsai, J. C., Hsueh, P. R., Lin, H. M., Chang, H. J., Ho, S. W. \& Teng, L. J. (2005). Identification of clinically relevant Enterococcus species by direct sequencing of groES and spacer region. J Clin Microbiol 43, 235-241.

Tung, S. K., Teng, L. J., Vaneechoutte, M., Chen, H. M. \& Chang, T. C. (2007). Identification of species of Abiotrophia, Enterococcus, Granulicatella and Streptococcus by sequence analysis of the ribosomal 16S-23S intergenic spacer region. J Med Microbiol 56, 504-513. 